\title{
El mediador insomne: Fredi Guthmann en Asia y las Islas del Pacífico
}

\author{
Axel Gasquet ${ }^{\bullet}$ \\ (Université Clermont Auvergne)
}

\section{Resumen}

Este trabajo intenta capturar el legado de la vida y obra Fredi Ghutmann (1911-1995), notable poeta y aventurero franco-argentino que viajó y vivió extensamente en varios países de Asia y el Pacífico. Su inconformismo intelectual y su temperamento rebelde, lo condujeron a desarrollar una obra fragmentada, sugestiva y lúcida, que dejó profundas marcas en grandes escritores del siglo XX, como Benjamin Fondane o Julio Cortázar. Examinamos aquí los dispersos testimonios de su obra póstuma, contenidos en cuatro ediciones que reúnen sus poemas, correspondencia y álbumes fotográficos.

\section{Palabras clave}

· Fredi Ghutmann · legado · mediador · Oriente

\begin{abstract}
This paper attempts to capture the life and works legacy of Fredi Ghutmann (1911-1995), notorious Franco-Argentine poet and adventurer who traveled widely and lived in various countries of Asia and the Pacific. His intellectual nonconformism and rebellious character, led him to develop a fragmented, suggestive and lucid work, which left deep marks on great writers of the twentieth century, as Benjamin Fondane or Julio Cortazar. We examine here the scattered evidence of his posthumous work contained in four books with poems, letters and photo albums.
\end{abstract}

\section{Key words}

· Fredi Ghutmann · legacy · mediator · Orient

\footnotetext{
- Doctor en Letras por la Universidad de París X; egresado de la Universidad de Buenos Aires y la EHESS de París. Es catedrático de Literatura y Civilización Hispanoamericanas en la Universidad Clermont Auvernia (Francia) e investigador titular del CNRS en el Institut d'Histoire des Représentations et des Idées dans les Modernités (IHRIM). Sus obras monográficas más recientes son: El llamado de Oriente. Historia cultural del orientalismo argentino (1900-1950) (Buenos Aires, EUDEBA, 2015), El cielo protector, la literatura de viajes (Perú, Ediciones Aquelarre, 2015), La heredad del silencio. Escritores franceses heterodoxos (México, Universidad Veracruzana, 2008).
} 
Examinaremos el legado oriental de Alfredo Jonás Guthmann (1911-1995), discreto explorador, fotógrafo y poeta argentino, procedente de una familia judía alsaciana. Conocido por sus amigos como «Fredi», su desahogada posición familiar le permite satisfacer su inmensa curiosidad por los pueblos y culturas del Asia y el Pacífico. De cultura cosmopolita (era bilingüe español-francés y hablaba corrientemente el alemán), su formación intelectual autodidacta le reserva un papel de mediador intercultural en la literatura franco-argentina. Ávido lector de poesía, fue amigo íntimo de Julio Cortázar y oficia como passeur de las culturas orientales para con su amigo escritor (el personaje "Oliveira» de Rayuela está en parte inspirado en Fredi). Frecuentador de los cenáculos literarios y artísticos franceses (amigo de André Breton, Antonin Artaud y Benjamin Fondane), en el Río de la Plata traba relación con los escritores argentinos Oliverio Girondo, Eduardo Mallea, Daniel Devoto, Aldo Pellegrini y los artistas plásticos uruguayos Joaquín Torres García y Pedro Figari.

Su obra poética permaneció inédita y fue escrita en francés (Venturini, 2011). Sus muchos poemas y carnets de viajes fueron editados póstumamente por su viuda, Natacha Czernichowska. Se editan dos títulos con sus poemas, el primero bilingüe y el segundo en francés: La gran respiración bailada/La grande respiration dansée (1997) y Le grand matin définitif (1998). Más recientemente, los testimonios fotográficos de sus expediciones por Asia y el Pacífico fueron reunidos en sendas ediciones francesa (2004) y argentina (2009), que incluyen numerosa correspondencia, junto a textos de y sobre el autor.

A través de esta obra rica y fragmentaria, testimonios vivos de su fascinante universo intelectual y espiritual, trataremos de resumir su personalísima visión de las culturas del Pacífico, China y la India, país este último en donde el matrimonio Guthmann vivió durante dos tumultuosos años, poco después de su independencia. 


\section{Semblanza biográfica}

Alfredo Guthmann nace en San Isidro el 12 de noviembre de 1911, en el seno de una familia judeo-alsaciana hostil a la anexión alemana de Alsacia tras la guerra franco-prusiana de 1871. Su padre fallece cuando Fredi tenía apenas dos años, y su hermano mayor, Georges, tres. De Buenos Aires su madre regresa a Estrasburgo junto con sus dos hijos, donde Fredi realizará una escolaridad brillante, llegando a ser con apenas trece años el bachiller más joven de Francia. Sin embargo, en 1925 el joven Fredi padece el repentino fallecimiento de su madre, víctima de una intoxicación, y tras este infortunio decide no emprender estudios superiores. Su tío francés, Simón Guthmann, asume entonces la tutoría de los hermanos. Fredi inicia una etapa de gran turbulencia, marcada por una indomable rebeldía contra el dictado familiar, que alentaba en ellos el éxito social y la prosperidad económica; dicho mandato es en cambio aceptado con docilidad por su hermano mayor, que será médico. Fredi sigue en un primer momento a su hermano Georges a París. A los diecisiete años viaja por Yugoslavia; despojado de sus pertenencias por un truhan, debe apañarse durmiendo en los cementerios. Con dieciocho años la familia lo envía de regreso a Buenos Aires para aprender el oficio paterno, que fue joyero, para reiniciar el lucrativo negocio familiar. En poco tiempo se convierte en un experto; pero los negocios lo aburren. Con apenas veinte años parte hacia Polinesia y Melanesia. Navegador solitario, permanecerá explorando diversas islas entre 1931 y 1932 [Foto 1], acompañado en ocasiones por dos jóvenes australianos [Foto 2]. Visita y convive con diversas tribus antropófagas en Malakula [Fotos 3 \& 4], en el archipiélago de Vanuatu. La vida aventurera lo exalta, «estoy más orgulloso de mi vida que de mi obra», había sentenciado con tono perentorio con apenas diecinueve años.

En 1933 regresa a París y establece pronto contacto con los surrealistas, trabando relación con Antonin Artaud y André Breton; pero establece sobre todo una estrecha y duradera amistad con Benjamin Fondane, escritor judío rumano emigrado en Francia. Los primeros lo invitan a publicar sus poemas, pero Fredi declina pues no considera el momento oportuno para difundir su obra. Aunque la propuesta era halagüeña, Fredi juzga en efecto el ofrecimiento muy desproporcionado: «Breton era una luz —afirma - y nosotros las polillas alrededor» (Guthmann 2009: 166). En 1934 emprende una nueva aventura y parte rumbo a Tahití, las Islas Gambier y los mismos sitios del primer viaje. De la Polinesia pasa luego a Japón y China; en este último país permanece cierto tiempo en medio de una situación política convulsa. El inicio de la guerra en Manchuria y el Pacífico frenan su ardor viajero; Fredi regresa a Buenos Aires y comienza a frecuentar a la élite literaria y plástica porteña.

En su ciudad natal conocerá a Natacha, su futura esposa. Promediando la década de 1940 Fredi se liga en amistad con el joven Julio Cortázar, recién llegado de Mendoza, donde había pasado año y medio como profesor titular de literatura francesa en la recién creada Universidad Nacional de Cuyo (Correas 2014: 
25-32). Organiza en Buenos Aires, en la Galería Muller, las primeras exposiciones del célebre pintor uruguayo Joaquín Torres García (fundador del universalismo constructivo). Terminada la segunda guerra mundial regresa a París y por intermedio de Pierre Loeb conoce a Pablo Picasso, con quien tiene varias entrevistas; a comienzos de 1948 visita nuevamente a Artaud en el hospicio de Ivry; en Italia se lía en amistad con el pintor esloveno Zoran Music. En Buenos Aires se casa con Natacha en 1949 y parten juntos a vivir dos años en la India, que acababa de lograr su independencia. Este será un hecho capital en la vida aventurera y dislocada de Fredi Guthmann; en la India su espíritu insatisfecho encuentra al fin una respuesta mística a sus inquietudes y desasosiegos. El impacto de la cultura y el pueblo hindú es tan determinante que Fredi deja de escribir poesía a partir de esos años. Su espíritu torturado y alma fragmentada desde la infancia por las vicisitudes familiares, encuentra al fin sosiego y recobra cierta unidad. Analizaremos este punto más adelante, recomponiendo parcialmente este episodio con sus textos póstumos.

En 1951 el matrimonio Guthmann regresa de la India y se afinca definitivamente en Buenos Aires, intercalando regulares viajes a Francia y Europa. Fredi se ocupa de la joyería y participa activamente de la vida cultural y artística porteña, prosiguiendo con voracidad la lectura de poesía y filosofía mística. En 1970 se retira de los negocios y cierra la joyería; poco después el matrimonio se instala en Mar del Plata, donde residirán por casi veinte años, alternando con estancias en Buenos Aires y frecuentes viajes a Europa. En 1992 Fredi sufre un infarto cerebral que lo priva del habla, pero sigue leyendo incesantemente. Fallece en la ciudad balnearia el 8 de enero de 1995.

\section{Los pueblos del Pacífico}

Según trasuntan sus textos dispersos, para Guthmann la aventura es primordial y fundadora, insuflando un sentido a su vida. Pero no se trata en absoluto de la aventura como performance. Al contrario, la aventura es una dimensión vital de la intimidad existencial, una forma de reencuentro con su identidad dislocada. Fredi busca por los caminos del mundo lo inhallable (esto es, el «sentido poético»), que otros creen encontrar aferrándose al orden y la seguridad material. Para Fredi sólo la poesía es capaz de dar relativa cuenta (en modo subjetivo y transitorio) del caos de la vida real y su efervescente multiplicidad; la aproximación poética del mundo es la única vía para recobrar el equilibro dentro del desajuste inconfortable (principio ontológico) que se establece entre el hombre y la realidad. Los versos de Benjamin Fondane citados en el epígrafe van en la misma dirección que el desarraigo nómade de Guthmann. Ambos están atravesados por una aspiración absoluta (una afirmación): captar y poseer todas las infinitas determinaciones del hombre. Esto es lo que Fredi distingue como el «sentido poético»: una comunión profunda con la alteridad humana.

Los documentos de sus viajes por las Islas del Pacífico se componen de cartas [Fotos 5 \& 6] y fotografías. Las primeras están destinadas en gran medida a su hermano Georges, que ejerce la medicina primero en Francia y, después de la guerra, en la 
Argentina. Georges era la antítesis de Fredi, pero sin embargo compartían una gran complicidad afectiva y profunda sensibilidad artística (su hermano se interesaba también por la pintura y la escultura). La fotografía fue una constante pasión juvenil de Fredi; a pesar de su inmensa sagacidad visual, nunca se vanaglorió de esta actividad. Discreto, apenas menciona en su correspondencia su intensa labor fotográfica. Altruista y desprendido, entrega numerosos clichés tomados en las Nuevas Hébridas (nombre colonial de Vanuatu) a su amigo Tom Harrisson, de la Universidad de Oxford. Este las publica como ilustraciones de su completo estudio antropológico sobre los indígenas de Vanuatu (Savage Civilisation, 1937) ${ }^{1}$ [Fotos 7 \& 8]. Explícitamente Fredi no quiere aparecer como autor de las fotos, pero el antropólogo británico igual lo incluye en sus agradecimientos (Harrisson 1937: 8). Durante la segunda guerra mundial, Harrisson, que estaba de regreso en el Pacífico, le escribe a su amigo en Buenos Aires proponiéndole realizar una nueva expedición conjunta entre los Big Nambas de Malakula. Pero Fredi declina el ofrecimiento por el alto riesgo que entonces supone la travesía marítima de Sudamérica al Pacífico. Tras dicha expedición Harrisson editará su segunda obra: Living Among Cannibals (1943). Otros tantos objetos de arte tribal traídos del Pacífico son cedidos por Fredi al etnólogo y coleccionista Paul Rivet, el célebre fundador en 1937 del Musée de l'Homme de París, donde son exhibidos durante treinta años con el nombre del testador.

El legado epistolar de Fredi, escrito en francés y también publicado en forma póstuma, da cuenta de su visión profundamente crítica del colonialismo europeo en el Pacífico. Fredi denuncia el egoísmo y la explotación de los colonos hacia los pueblos nativos y la gran hipocresía de los misioneros cristianos, a quienes considera cómplices directos de la empresa colonial. Sus viajes están motivados por una busca intensa de los valores humanos en la alteridad más radical, que asimismo constituye su gran ambición poética y existencial. Por tal razón Fredi Guthmann, dondequiera que vaya, intima fácilmente con los locales y se abandona a la sensualidad de las mujeres nativas (la dimensión erótica del viaje está siempre presente en su correspondencia) [Foto 9]. Su experiencia con los pueblos primitivos es más que una simple audacia de aventurero: constituye la búsqueda inextinguible de una exigencia íntima y personal, metafísica y trascendente: el contacto con la alteridad radical le proporciona «los elementos de ese simbolismo bárbaro que es la clave de sol para nosotros» (Natacha Guthmann, 2009: 20. Subrayado nuestro).

Esta busca existencial del joven viajero es solitaria y el espíritu taciturno impregna a menudo su cotidiano. Pero Fredi conoce las razones que lo empujan a prolongar indefinidamente su periplo por el Pacífico. Escribe a su hermano:

No tengo decidida la dirección: dudo entre ir a Japón o dirigirme a Francia. La perspectiva de regresar con ustedes es algo infinitamente delicado: por un lado me sigo sintiendo incapaz de entrar en cualquier sociedad organizada, inadaptado, y también la secuela de dolores ocultos [...] (Ibidem, carta XII: 51).

Durante su segundo viaje de 1934, con tono introspectivo escribe Fredi otra carta a su hermano Georges:

La melancolía se ha adherido a mis talones y no me libraré de ella sino aislándome lejos de los mercados, de las ciudades. Mi experiencia va hacia su etapa crítica. El futuro me parece disponible, me refiero al futuro espiritual; ¿̨acaso el destino se pondrá a solicitar más fuertemente 
mi vida? ¿Quién sabe? [...] La unión de todo lo que fue vivido y de lo que será sólo se realizará en la mente. [...] Me hace falta un equilibrio permanente para lo que debo ser y debo hacer y estoy cansado de ser un fragmento, un shrapnel [una esquirla], y de no expresarme más que en fragmentos. He regresado a la Polinesia después de un triste año en Francia. (Ibídem, carta XVI: 58-59. Subrayado nuestro)

Critica también sin remilgos la 'estrechez mental' de la sociedad colonial en Nueva Caledonia. En Numea concluye sus observaciones del siguiente modo: «[...] el infaltable complemento de sus falsas mujeres engalanadas; la sórdida politiquería de los colonos desgraciados. También estoy cansado de la bajeza humana. Todos se admiran; la mujer especula; no hay nada más potable que la estupidez cuando se acompaña con sencillez» (Ibídem: 59). Su experiencia en el Pacífico se resume en un fuerte rechazo de la sociedad colonial, anverso de su entrega absoluta para con los pueblos nativos [Fotos $10 \& 11$ ]. Fredi explora las dimensiones infinitas del encuentro con el otro; sólo en este encuentro con la alteridad se siente a gusto y recobra la ansiada unidad perdida de su existencia.

Todo un mundo separa a Fredi de la vida de los colonos franceses en Nueva Caledonia o las Nuevas Hébridas (Vanuatu). Los Guthmann son una familia judeo-alsaciana desarraigada que viven en un prolongado estado de exilio mental, pero este sentimiento y esta identidad nómade es el resultado de múltiples factores que se combinan y que lo aproximan a la estampa clásica del «judío errante»: ni alemán (aunque habla esta lengua), ni completamente francés (litigiosa tierra de sus ancestros), ni integralmente argentino (país natal al que vuelve ya adulto), ni del todo judío por tradición (pues recibió una educación secular y laica). Su «disponibilidad» mental y espiritual es absoluta, posee una cultura cosmopolita y políglota, sus holgados recursos financieros provienen de una actividad económica urbana y elitista (la joyería); estos elementos alcanzan para situarlo en las antípodas de la mentalidad colonial europea: los colonos franceses (y europeos en general) provenían mayormente de las clases sociales medias (funcionarios de la administración colonial), medias-bajas (artesanos) o francamente populares (campesinado). Con excepción de los funcionarios — que solían transcurrir pocos ańos en el destino asignado antes de obtener como promoción un traslado a la metrópoli o a una colonia más cercana a ésta-, las otras dos categorías populares eran familias que habían llegado a los nuevos territorios para afincarse y construir un nuevo destino bajo otros cielos, lejos de las difíciles condiciones metropolitanas. A la dificultad de tener que arraigarse en estas nuevas tierras, el colono debía 'justificar' su condición de colono legitimando su presencia con la misión de tutela civilizadora que su rol suponía respecto a los pueblos nativos; éste era el modo de asumirse como una nueva clase de propietarios coloniales frente a la legitimidad de la posesión de la tierra reclamada por los autóctonos.

Dentro de dicho cuadro social, Fredi Guthmann era visto como un observador foráneo que no encajaba con ningún criterio de la jerarquizada sociedad colonial. En fin, Fredi constituyó una suerte de anomalía en todos los sentidos sociales del término: demasiado culto para identificarse con la rudeza del medio colonial; demasiado cosmopolita para identificarse con las necesidades del colono; demasiado conocedor de la cultura francesa para ignorar sus defectos; demasiado privilegiado económicamente para ser una simple familia de inmigrantes en la Argentina; demasiado judío para coincidir con los imperativos de conquista es- 
piritual de los misioneros cristianos; demasiado secular para identificarse con la cultura judía tradicional; demasiado citadino para sentirse cerca de la tierra... En definitiva, toda la existencia misma de Fredi Ghutmann, su condición particular de «joyero-aventurero" y de bohemian gentleman drifter, era demasiado marginal para asimilarse con el rígido orden social de las colonias.

\section{China y Japón}

Tras haber encauzado los negocios de la joyería en Buenos Aires en el plazo de dos años y medio, en 1938 Fredi Guthmann reemprende nuevamente su camino de peregrinación existencial. Viaja por Sudáfrica, las Islas Seychelles, Singapur y Vietnam, pero de estas experiencias quedan escasos y fugaces testimonios. Sólo las dos grandes naciones del extremo asiático han dejado constancia en sus impresiones epistolares. Durante su paso por China describe dos tragedias en una: las luchas intestinas entre los «señores de la guerra» y el reciente inicio de la guerra chino-japonesa, ambos eventos traumáticos. Una alocada carta a su hermano Georges desde Shanghái da cuenta ello:

\footnotetext{
A las puertas de Shanghái hay una masacre, estalla una bomba de un terrorista chino en el patio de mi hotel: me despierto y vuelvo a dormirme, son las dos de la tarde; mueren de cólera, un niño se retuerce de dolor sobre la calzada: yo escribo poesía; grito «Dios mío es fácil ser forjado de alegría». Me río, me parecen tan hermosas las chinas, son delicadas como el azul de los párpados, los chinos mueren, se venden sus fotos, muñones y tripas en la vereda, en los escaparates de Hong Kong. [...] Hermano mío, no puedo describir todo lo que he vivido aquí con una intensidad trágica. Tal vez algún día mi obra dará cuenta de ello. (Ibídem, carta XXIV: 72-73)
}

Pero tras el caos civil y la miseria observada en China [Fotos $12 \& 13]$, Fredi logra rescatar otras impresiones atenuantes del pueblo chino, cuya actitud resulta heroicamente estoica en medio de la tempestad:

He visto China, un pueblo tierno, infinitamente paciente y sabio, infinitamente querible, que sonríe desde el fondo de su miseria de muy, muy lejos. China con su pueblo inocente, cruel y mártir, cruel más allá del entendimiento, mártir más allá del entendimiento. He visto a las chinas, he visto a esas amigas pueriles, y por haberlas visto y haberles hablado lloré. ¡Ah, cuánta dulzura y cuánta buena voluntad para comprender, para saber, para ser felices! (Ibídem: 75)

Para concluir con irremediable melancolía, con un tono que denota amargura y pesadumbre: «el corazón del hombre consciente destila justicia y esa justicia golpea el cuerpo inexorable de la vanidad como una pequeña china que hubiese llegado con el corazón lleno de inútil ternura» (Ibídem: 75).

Meses antes, un mensaje telegráfico lo alcanza en Victoria (Mahé), capital de las Seychelles, con la noticia del fallecimiento en París de su tío Simón. De esta atormentada pérdida da cuenta Fredi en una nueva misiva para Georges enviada desde China, asociando el placer con la muerte: 
Hermano mío, en esta carta, me temo, verás, siempre bajo mis palabras demasiada tristeza. Pero aún tengo en mí el gran espacio vacío del cuerpo ausente del viejo (el tío Simón) muerto en París, mientras yo soñaba bajo las nubes del Océano Índico, mientras yo regateaba el cuerpo de una pequeña virgen de las islas Seychelles, mientras yo sońaba a la luz de la luna. Mientras yo escribía: «y la mujer enciende los elefantes de la caricia nocturna» [...] (Ibídem: 75)

El joven de veintisiete años continúa adelante por los caminos de Oriente, insomne, viendo mundo para mejor encontrarse, recolectando los fragmentos de su consciencia para poder cimentar su frágil existencia. Por eso su experiencia mental es fundamentalmente metafísica — aún no ha encontrado la piedra angular del edificio—. Japón, en cambio, lo impacta positivamente: «Nunca antes tuve la impresión, al visitar a un país, de haberlo conocido desde siempre. Digo: es esto, es más que esto». Fredi Guthmann no se demora demasiado en la ciudad, recorre en cambio la campiña nipona tratando de descifrar un "código desesperado». Frecuenta asimismo los burdeles y las casas de geishas:

[...] Tal vez entienda mal el artificio de lo japonés si de ello deduzco un enorme asco metafísico por la vida, por la lucha, por el verdadero rostro. [...] ¿Hay un arte, hay un instinto más profundo que ese cuidado secular para formar una muñeca del amor? ¿Acaso es un refinamiento o una necesidad de ídolo, flor de ironía del hombre y de la muerte? Pero creo que no lo entiendo: burdeles semejantes a jaulas... y sus mujeres... mariposas. (Ibídem: 73).

En semejante magma Fredi no halla aún el sentido poético del mundo y la forma adecuada de integrarse a él, no está en paz con el mundo porque no puede estar en paz consigo mismo. Sigue buscándose en cada recodo del camino, pero ahora asoma en su consciencia una misión tutelar.

Tal vez esté cerca la hora en que, aceptándome a mí mismo sin protestar más, aunque arrebatado de piedad por mí, por mi condición, habré de dar este corazón a los hombres. Es posible que dos o tres seres en el mundo se sientan limpiados con ello, se sientan recompensados y eso sería bueno, sería suficiente. Habré dado aquello por lo que nací, aquello por lo que fui llamado. Algo en el aire viene a calmar mis sienes. Tal vez la conclusión de todas mis andanzas, de todo ese amor, haga que una palabra llegue a mis labios, una de las primeras que tuve cuando era casi un niño, una de las que me puso de pie hacia la forma que yo debía ser: «Las hojas caen... y caen / Entonces, tú que fuiste el pasajero nocturno...» (Ibídem: 76).

Desde el confín de la Indochina francesa, en una última esquela del periplo redactada desde Hanói, Fredi intuye a fines de septiembre de 1938 que una nueva noche oscura se cierne sobre el teatro europeo (el oriente asiático ya estaba en guerra). Se trata de una oscuridad premonitoria y apocalíptica:

El bien y el mal conforman los mayores signos alguna vez aparecidos hasta este día, inextricablemente confundidos en su vuelo. [...] Es hora de avanzar de cara al destino, con el rostro descubierto. Durante estos últimos días he sentido una gran desnudez de corazón. Y si todo "se arregla» de nuevo: será entonces de nuevo la hora de la bestia con máscara trágica, la hora en que los judios servirán para pagar la insostenible miseria de los demás. (Ibídem: 76. Destacado nuestro) 
Semejante elocuencia prescinde de comentarios y glosas, pero en forma retroactiva resulta evidente su clarividencia respecto a la sombría noche que se cernía sobre el mundo. Tiempo después, iniciado ya el conflicto europeo y de regreso en Buenos Aires, Fredi colabora con el centro gaullista en la Argentina y subviene financieramente a su amigo Benjamin Fondane, que poco después, en París, es denunciado por su condición de judío a la Gestapo y será exterminado en Auschwitz-Birkenau. Su terrible corazonada en Hanói, como en una pesadilla, se convierte en trágica y banal realidad.

\section{El cénit espiritual de la India: Fredi y un tal Julio Cortázar}

En pareja con Natacha desde 1939, parten juntos rumbo a París en 1948. En Francia se casarán en 1949 y se encaminan hacia la India por un viaje de más de dos años [Fotos 14 \& 15]. En plena madurez, este viaje representa el inicio de una nueva vida. En el sur de la India visitan al maestro espiritual Ramana Maharshi. La experiencia mística en el ashram y las nuevas lecturas filosóficas conducen a Fredi al encuentro de la unidad espiritual que tanto ansiaba. Alcanzada cierta serenidad y sosiego espiritual, Guthmann deja definitivamente de escribir poesía. Como afirma Louis Soler, «sigue amando la vida, la naturaleza, el arte, la belleza en todas sus formas; sólo que ahora ve las cosas a la luz de esta certeza interior que le fue otorgada. Fredi podrá, más que antes incluso, ocuparse de los otros» (Guthmann 1997: 11).

Entre los numerosos artistas plásticos y escritores a quienes presta ayuda, se cuenta el joven Julio Cortázar, de notoriedad todavía incipiente y a quién orienta en Buenos Aires y durante sus primeros ańos en París. Fredi es el «shamán [sic] de la calle Santa Fe» de La vuelta al día en 80 mundos, el chamán de «pudor inexpugnable» que «no escribirá nunca sus memorias" (Cortázar 2006: II, 155). La discreción de Fredi respecto a su obra es paralela a la importancia que cobra su marcada influencia entre sus amigos [Foto 16]. Una cabal idea del constante sostén moral e intelectual que Cortázar tuvo de Fredi Guthmann, aparece asentado en la abultada correspondencia que ambos tuvieron (quince extensas cartas en total). La edición póstuma de las cartas de Cortázar testimonia sobre la superioridad espiritual que éste le asignaba a su amigo y mentor. Estas cartas delinean el cambio fundamental que la estancia en la India había operado en la exaltación existencial de Fredi, alcanzando allí cierta serenidad, y frente a la cual Julio Cortázar siente que sus certezas intelectuales zozobran. Ambos amigos se encuentran en París cuando los Guthmann regresan de la India camino a la Argentina. Escribe Cortázar con fecha del 3 de marzo de 1952:

Lo que puedo decirte (y esta tonta carta tiene ese objeto) es que en ti veo la presencia viva de eso que tus palabras no alcanzan todavía — por mi enorme ignorancia - a mostrarme con claridad. Tú has vuelto de allá con ojos nuevos. Ya te lo dije anoche, y es cierto. Tu cara es la misma, pero te han cambiado la mirada. Tenías una mirada huyente, acechadora, analítica. Ahora miras y ves de una manera que mi propia mirada siente profundamente. En cuanto a tus palabras, espero humildemente entenderlas mejor si tienes el deseo de continuarlas para mí. No sé lo que pasará, porque la batalla es dura y yo me he conformado hasta hoy con lo 
que tenía y alcanzaba. Pero el hecho de que haya una batalla te prueba (y me prueba) que nuestro encuentro de anoche no ha sido inútil ni estéril. Quisiera que me creas digno de seguir escuchándote. (Cortázar 2000a: 267).

El Cortázar de los primeros encuentros con Fredi, promediando los años 1940, ya era consciente del caudal de lucidez existencial de su amigo cosmopolita. Así lo indica en su primera carta, cuando por falta de confianza todavía Julio lo trataba de Usted:

Siempre me pareció ver en usted (jy lo he conocido tan poco y tan mal!) una situación muy clara y definida, como la del hombre que a mitad de la vida se ha quitado ya de encima todo o casi todo lo accidental, lo transitorio. Incluso su tendencia a desplazarse, a ir de un lado a otro, me pareció un afán de no enraizarse, de no recaer en la triste condición del hombre que tiene una sola casa, una sola mesa, un solo libro, una sola ventana con un solo paisaje. Simplificación, y a la vez enriquecimiento. Por eso me parece que usted va admirablemente preparado para su experiencia oriental. Vous allez boire à la source, mais c'est parce que vous le méritez... (Ibídem: 233)

A mediados de 1951 Cortázar le escribe desde Buenos Aires a su amigo que se hallaba en la India: «usted tiene ya le lieu et la formule. [...] Ahora comprendo que el avance de su espíritu es menos un desasimiento que un asimiento, una comprensión final y profunda de esta realidad que yo comprendo sin finalidad y sin profundidad» (Ibídem, 256) [Foto 17]. La senda ondulante emprendida por Fredi le seduce intelectualmente a Cortázar (quizá porque él sabe que no podrá adentrarse en este camino zigzagueante), pero es incapaz de seguirlo en el plano sensible. Cortázar no puede acompañar a su aventajado amigo en este intrincado derrotero espiritual. Julio está muy apegado a un tropismo de valores occidentales, americano y europeo, del que no puede ni quiere distanciarse. Entusiasta, Cortázar realiza en 1956 su primer viaje a la India como traductor de la UNESCO para una conferencia internacional en Nueva Delhi. Pero tras un primer contacto con el país este entusiasmo se disipa pronto; la inicial fascinación por las tradiciones culturales indias da paso a un sentimiento de espanto. Cortázar no puede trascender su «fidelidad ciega» por Occidente (Barnabé 2013).

Esta primera impresión de Cortázar se acentúa con motivo de un segundo viaje profesional, en 1968. Oriundo de un país periférico, Julio siente verdadero «horror» frente al panorama social de los hindúes.

La India — le escribe en aquella ocasión a Julio Silva — me muestra horriblemente lo que es el tercer mundo, y me siento muy mal y con una constante crispación de estómago; no soy, desde luego, el esteta que era en 1956, cuando me limitaba atentamente a ver lo bello de la India sin preocuparme demasiado por el resto, que es casi todo» (Cortázar 2000b: 1237).

El escritor consagrado de Rayuela (1963) deja atrás sus mesuradas apreciaciones estéticas de la India y privilegia ahora sus observaciones políticas. Las consideraciones espirituales otrora sugeridas por Fredi Guthmann se han alejado definitivamente de su espíritu.

Sin embargo, su amigo lo acompaña desde la distancia en esta empresa de aprendizaje y asimilación espiritual. De hecho, Guthmann es el modelo empleado por Cortázar para la elaboración de los soliloquios del personaje capital de Rayuela, Horacio Oliveira. Así se lo confiesa en una carta de 1962, anterior a la publicación de su novela: 
[Rayuela] va a ser el libro donde me vas a encontrar a fondo, donde vos y yo hemos dialogado muchas veces sin que lo supieras. No es que seas un personaje de la obra, pero tu humor, tu enorme sensibilidad poética, y sobre todo tu sed metafísica, se reflejan en la del personaje central (Cortázar 2000a: 488).

Y poco después Julio aclara bien la diferencia que separa su personaje Oliveira —real depositario de su elección personal_- para con el derrotero seguido por Guthmann:

[...] he puesto todo lo que siento frente a este fracaso total que es el hombre de Occidente. Contrariamente a vos, el personaje central no cree que por los caminos del Oriente se pueda encontrar una salvación personal. Cree más bien (y en eso se parece a Rimbaud) que il faut changer la vie pero sin moverse de ésta. Entrevé esa vieja sospecha de que el cielo está en la tierra, pero es demasiado torpe, demasiado infeliz, demasiado nada para encontrar el pasaje. (Ibídem)

\section{Conclusión: explorador insomne}

Hasta edad avanzada Fredi Guthmann tuvo siempre la idea que su vida era fragmentaria y despedazada. Persiguió la «unidad» fundamental como otros buscan el Santo Grial o atisban el pan de cada día. Fue un explorador insomne: conquistador de los recodos y rescoldos insondables del alma, fue al encuentro del mundo y supo perderse en él (sin esperar nunca que los ecos del mundo viniesen hasta él). Nacido en una familia acomodada tomó permanentemente riesgos insensatos, por fuera de todo cálculo. Su obra poética y artística fue inconclusa, $a$-sistemática, dislocada, porque la obra de su vida fue su propia vida [Foto 18]. Nunca escatimó con premeditación los encuentros; al contrario, inmoderado, los propiciaba sin retaceos y se brindaba a su entorno sin recelos, de alma entera. Fredi era un excepcional "pararrayos de piantados", según la feliz fórmula empleada por Cortázar (2006: 155). Su verdadero arte, incandescente y fugaz, era el ser orfebre de su vida y eterno passeur de las vidas que gravitaban en su entorno (fue para sus amistades un tenaz punto de convergencia centrípeta y, al mismo tiempo, el origen de sus refractarias líneas de fuga). Esta modesta y trascendental misión fue aquello para lo que nació, fue aquello para lo que estuvo llamado. Y Fredi logró en cierto modo su cometido. "C'est le grand matin définitify reza el verso de uno de sus poemas. Es el nuevo día, el día sin noche, la luz que fulgura en medio de la oscuridad; en fin, un homme éclairé [Foto 19].

El mundo brindaba por mi salud sin reposar el vaso

[...]

El mundo virulento se resquebrajaba en mí en el fondo

[...]

La vida me lame ella me es extrańa tan insondablemente

Más interior que yo mismo (Guthmann 1997: 81) 


\section{Anexo fotográfico}

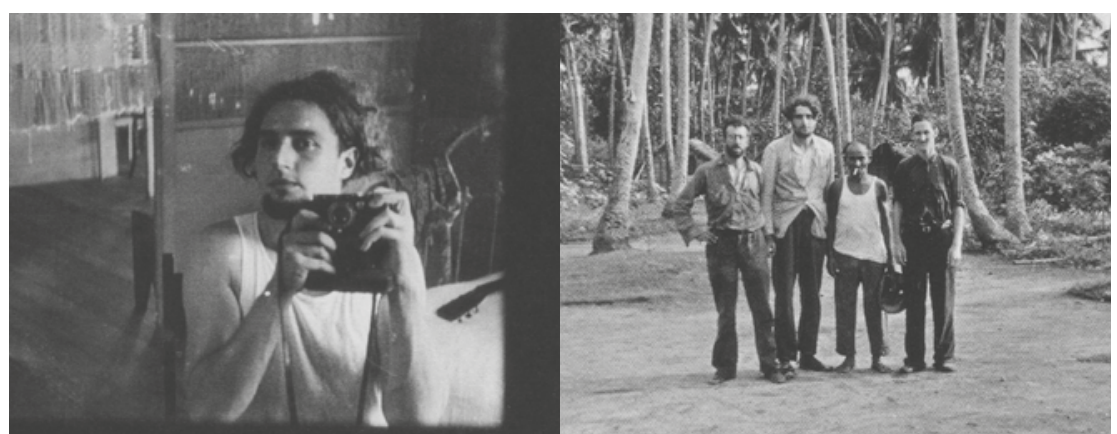

Foto 1. Autorretrato de Fredi

(Tahití, Polinesia francesa, 1932).
Foto 2. Fredi y la tripulación australiana de Pacific Moon (1932).

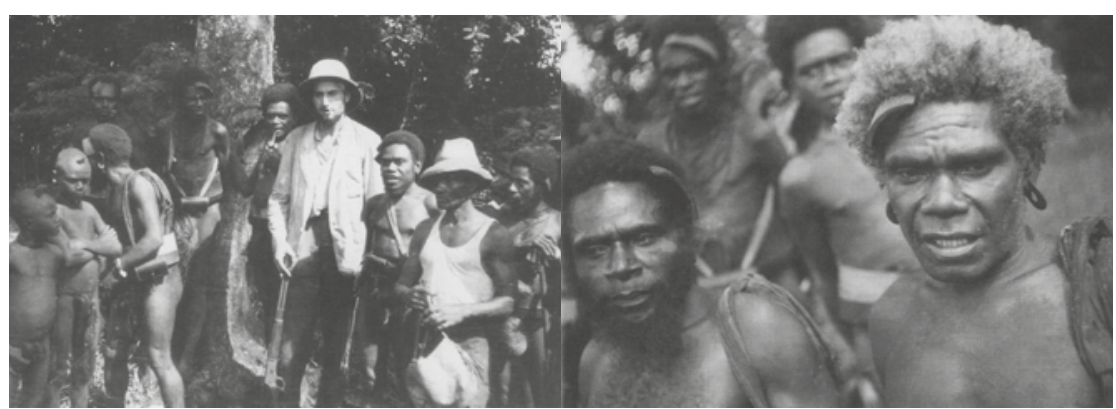

Foto 3. Fredi con indígenas en Malakula (Vanuatu, 1933)

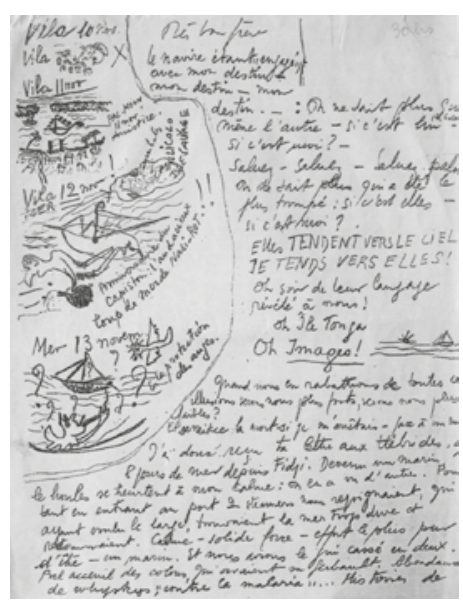

Foto 5. Manuscrito

(Port Vila, Vanuatu, 1933).
Foto 4. Nativos de Malakula (Vanuatu, 1933).

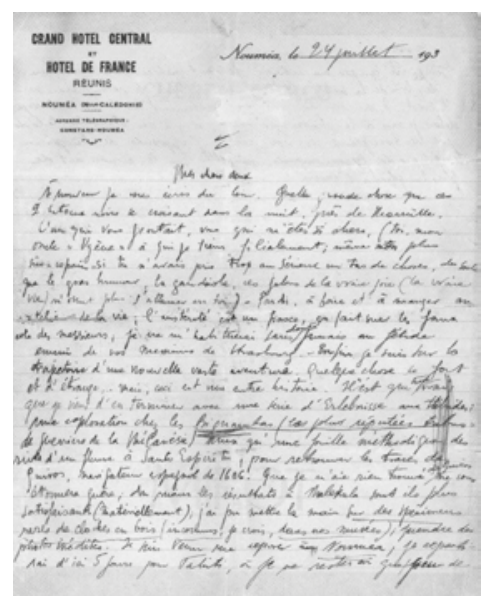

Foto 6. Carta manuscrita

(Numea, Nueva Caledonia, 1937). 


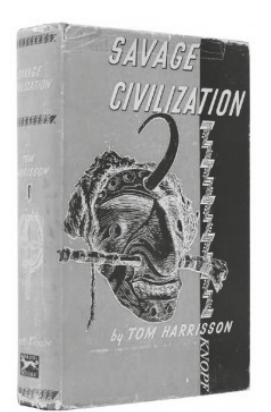

Foto 7 \& 8. Savage civilisation (1937) y Tom Harrisson.

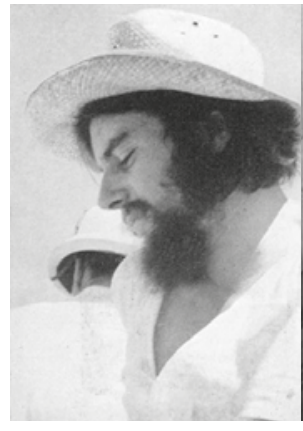

Foto 9. Muchacha polinesia

(Tahití, Polinesia francesa, 1932).
214215

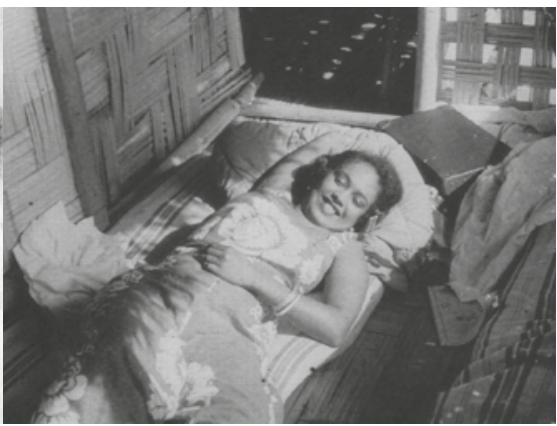

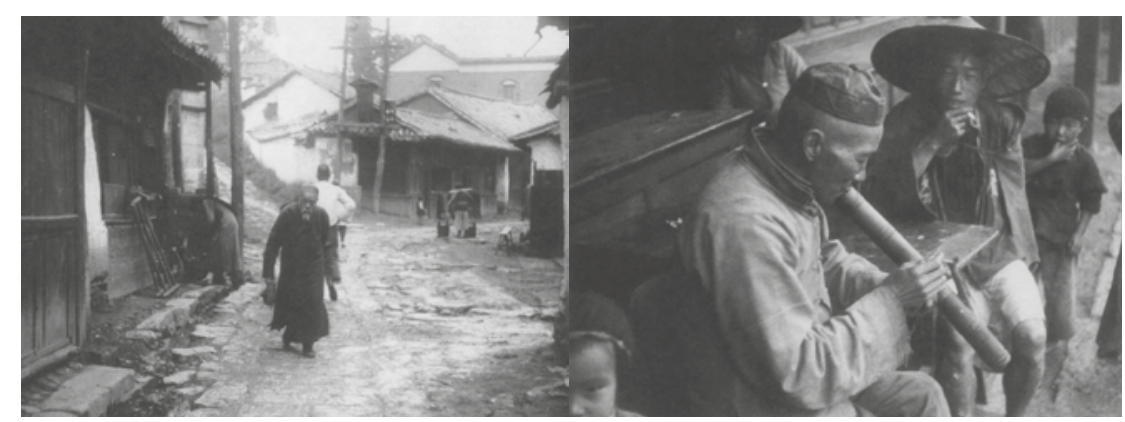

Foto 10. Escena callejera (China, 1938).

Foto 11. Fumador de opio (China, 1938)

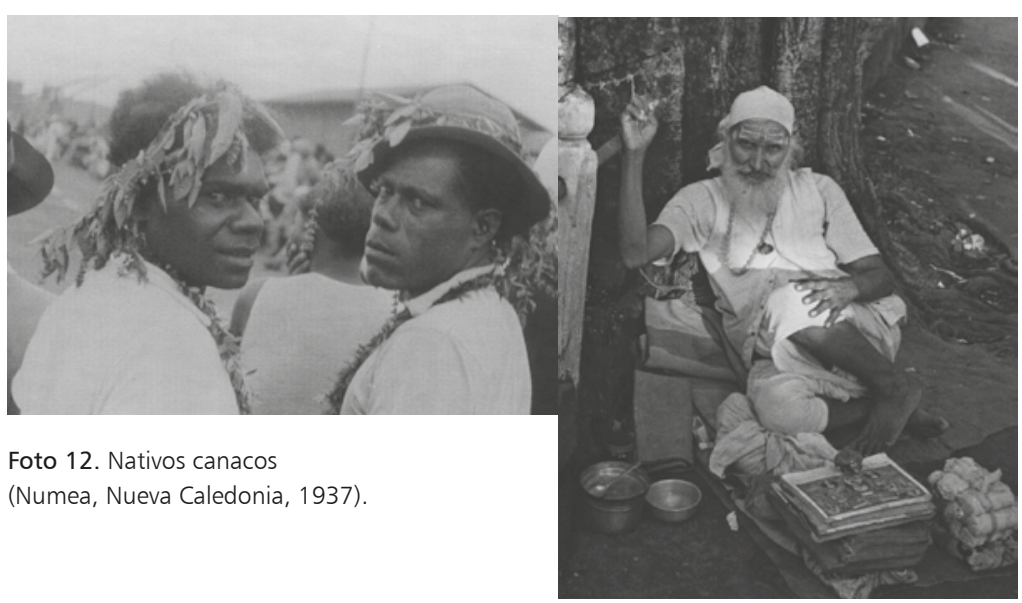

Foto 13. Norte de la India, 1949. 


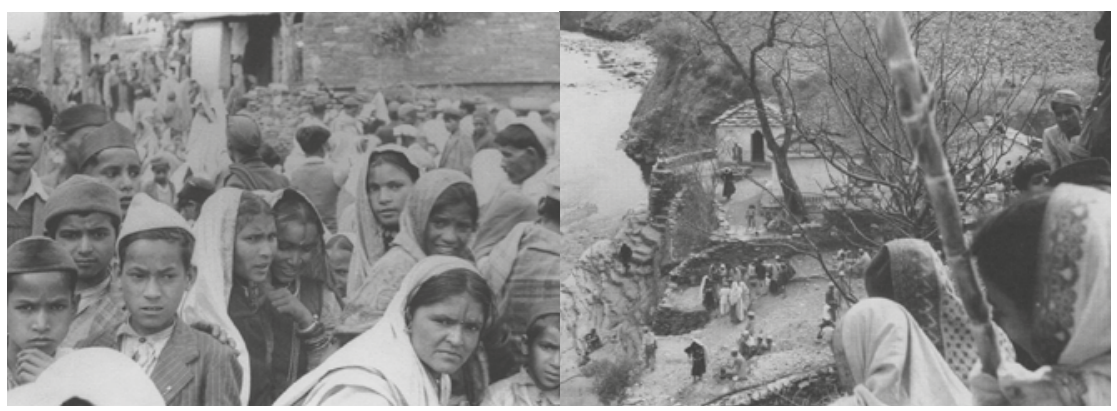

Foto 14. Himalaya,

Norte de la India (1949).

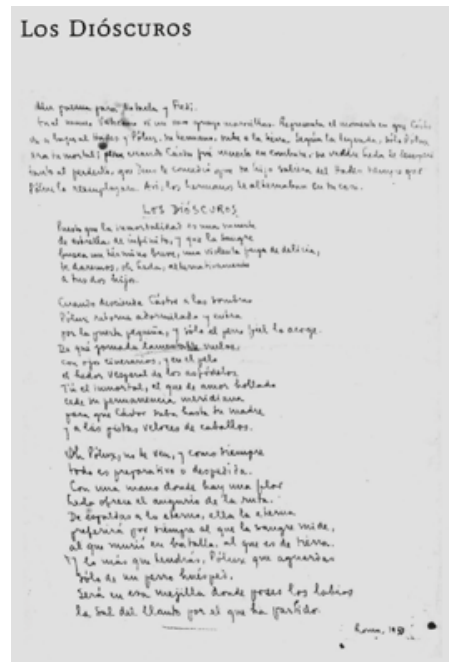

Foto 16. Poema manuscrito de Julio Cortázar a Natacha y Fredi (Roma, 1953).
Foto 15. Himalaya,

Norte de la India (1949).

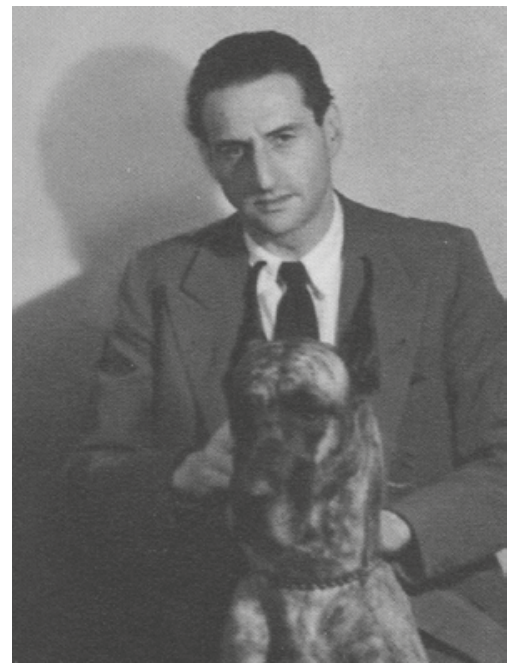

Foto 17. Retrato de Fredi

(Buenos Aires, 1947).

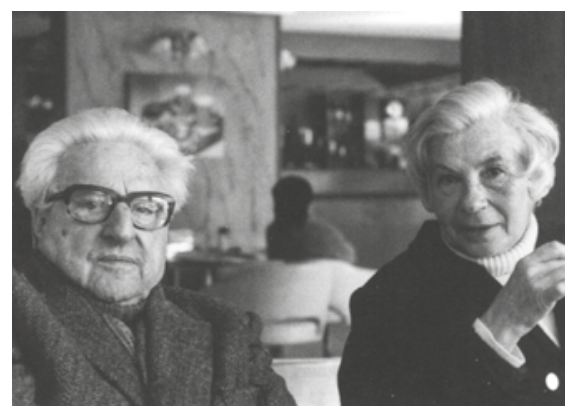

Foto 18. Fredi y Natacha Guthmann

(Mar del Plata, 1992). 


\section{Nota}

${ }^{1}$ Como Fredi Guthmann, Tom Harrisson nació en Buenos Aires el 26 de septiembre de 1911, en el seno de una familia británica, y pasó su infancia en la Argentina antes de establecerse en Inglaterra. Ambos amigos tienen una misma sensibilidad y comparten el gusto por la aventura. Naturalista y antropólogo, Harrisson transcurrirá una gran parte de su vida en el Pacífico y Asia (Borneo, Sarawak, Malasia), falleciendo accidentalmente en Tailandia el 16 de enero de 1976 (Heinmann 1998). En 2006, Sir David Attenborough, que conoció bien al antropólogo, realizó un documental sobre su vida emitido a inicios del 2007 por el canal 4 de la BBC: Tom Harrisson, The Barefoot Anthropologist (2007).

\section{Referencias bibliográficas}

BARNABÉ, J.P. (2013). «De la fascination à l'horreur: Julio Cortázar en Inde» en Dubost, J.P. y Gasquet, A. Les Orients désorientés, Déconstruire l'orientalisme. París: Éd. Kimé, pp. 253-264.

Correas, J. (2014). Cortázar en Mendoza, Un encuentro crucial. Buenos Aires: Alfaguara.

Cortázar, J. (2006). La vuelta al día en 80 mundos. Vol. I \& II [1967]. México: Siglo Veintiuno Editores.

(2000a). Cartas 1937-1963, 1. Buenos Aires: Alfaguara. (2000b). Cartas 1964-1968, 2. Buenos Aires: Alfaguara.

Harrison, T. (1937). Savage Civilisation. Londres: Victor Gollancz. (1943). Living Among Cannibals. Londres: G.G. Harrap.

Heimann, J.M. (1998). The Most Offending Soul Alive: Tom Harrisson and his remarkable life. Hawai: University of Hawai Press.

Guthmann, F. (1997). La gran respiración bailada - La grande respiration dansée. [Traducción de Rafael Felipe Oteriño]Buenos Aires: Atuel — (1998). Le grand matin définitif. Grigny: Éditions Paroles d'Aube.

(2009). Fredi Guthmann. [Prólogos de Rafael Felipe Oteriño y Louis soler. Traducción Silvio Mattoni (cartas) y Arturo Carrera (poemas)]. Buenos Aires: Letemendia Casa Editora.

Plantegenet, T. y Goldstein, M. (coord.) [2004]. Fredi Guthmann. Lettres, photographies et poèmes. París-Dunkerque: Somogy Éditions d'Art-Association Atout'Art.

Venturini, S. (2011). «Fredi Guthmann: el extranjero entre nosotros». El Hilo de la Fábula (11), 143-153. Santa Fe: Universidad Nacional del Litoral.

\section{Gasquet, Axel}

«El mediador insomne: Fredi Guthmann en Asia y las Islas del Pacífico». El hilo de la fábula. Revista anual del Centro de Estudios Comparados (19), 203-217. 